\title{
Quality Of Life among Caregivers of Elderly With Dementia and Its Associated Factors
}

\author{
NurFatihah O.A ${ }^{1}$,Rahmah M.A ${ }^{2}$, Rosnah $\mathrm{S}^{2}$, Ismail D ${ }^{3}$, Khadijah $\mathrm{S}^{4} \&$ ShEzat \\ $\mathrm{SP}^{4}$. \\ ${ }^{1,2,4}$ (Department of Community Health/National University of Malaysia, Malaysia) \\ ${ }^{3}$ (Sarawak General Hospital, Malaysia)
}

\begin{abstract}
Dementia is a progressive illness and it imposed a great challenge for the caregivers. The daunting tasks have an impact to the quality of life of these caregivers.

Methods:A cross sectional study was conducted in five major hospitals in Sarawak, Malaysia,from June until December 2011. The objectives were to determine the quality of life among informal primary caregiversof elderly diagnosed with dementia and its associated factors.The respondents were informal primary caregivers of dementia patients who were on follow-up at the psychiatric clinic in five selected hospitals. They were recruited purposively from a list of elderly dementia cases. Guided interview was carried out either during clinic appointment or home visit for those who were not present during clinic follow-up. A set of questionnaire including socio-demographic characteristics, caregiving characteristics, patient characteristicsand SF 36 questionnaire for measurement of quality of life was administered.

Results:Hundred forty five primary caregivers were interviewed. They had significant poor physical composite score (PCS) as compared to mental composite score (MCS $(p<0.05))$. Behaviour problem among patientsand being a Chinese carer were significantly associated with poor mental score $(p<0.05)$.Meanwhile being unemployed $(p<0.05)$ and taking care of severe type of dementia patients $(p<0.05)$ were significantly associated with poor physical score.

Conclusion: Dementia caregivers, experiencing poor physical and mental health. It was associated withChinese race, behaviour problems of the patients, employment statusand type of dementia..
\end{abstract}

Keywords: caregivers, dementia, factors, quality of life, Malaysia

\section{Introduction}

The emerging of cases of dementia is occurring worldwide ${ }^{[1]}$. The escalating number of cases was more prominent in less developed country including Malaysia ${ }^{[1,2]}$. It was related to the emergence of ageing population in the so called 'young' countries. Like many Asian countries, due to poor resources and filial piety norms the duties of caregiving still lay on the family shoulder ${ }^{[3]}$.In dementia caregiving, there will be positive and negative impact on the caregiver's life. The negative impact of dementia caregiving on quality of life were studied by various researchers from other countries ${ }^{[4,5,6]}$. A study done by Hughes et al ${ }^{[7]}$ which involved 1,594 respondents found that factors affecting quality of life were spousal-relationship, lower income and burden. A comparative study between non-caregiver and caregivers age more than 65 years old found that the quality of life is lower in caregiver group ${ }^{[8]}$. They also mentioned that it was not because of the caregiving task alone but it was also associated with patient-carer relationship, social support and life satisfaction. In developed countries various support from local community were given to the caregivers, however such support were not available in local setting.

Previous studies in other part of the world correlates that multitasking ${ }^{[9]}$ and various factors in the process of caregiving would put the caregivers in great danger of burden ${ }^{[10,11,12,13]}$ thus impaired their quality of $\operatorname{life}^{[14]}$. The process includes characteristic of caregiving i.e. duration of caregiving ${ }^{[15]}$, patient'scharacteristics ${ }^{[16]}$ i.e. type of dementia and caregivers own factors. However little is known about the quality of life and its associated factors in our setting. Understanding on this issue is essential to create appropriate intervention to this group. Therefore the objectives of this study were to determine the quality of life of informal primary caregivers of dementia and its associated factors.

\section{Methodology}

A cross sectional study was conducted involving informal primary caregivers of dementia patients from the psychiatry clinic from five major government hospitals in Sarawak. Informal primary caregiver is defined as unpaid caregiver who was the main people who provide most care and assistance in patient daily activities. Data were collected from early June to end of December 2011. The dementia patients acted as the proxy to recruiting caregivers. Hundred and forty five respondents were chosen purposively as they fulfilled the inclusion 
criteria.The purposive sampling was done because of small number patients. The inclusion criteria were the primary caregivers, above 18 years old and who look after the dementia patient aged 60 years and above with confirmed diagnosis of dementia. The exclusion criteria were non Malaysian, formal maid and taking care for less than 3 months. The guided interview was done either in the psychiatric clinic or home visit.

A pilot testing was done for questionnaire validation. Data were collected using questionnaires consists of socio-demographic questionnaire, patient characteristics, caregiving characteristics and SF36 to measure quality of life. Patients or care recipients characteristics includes type of dementiaand behavioural symptoms were identified based on clinical record by a specialist. A caregiving characteristic includes duration of caregiving in years and daily hours and sharing of burden among family members. Meanwhilequality of life was measured using SF 36. The SF 36 is a well-known and widely used instrument to measure quality of life in more than 200 diseasesand has satisfactory validity ${ }^{[17]}$. It was translated into Malay and validated ${ }^{[18]}$. These measurements consist of 36 items representing eight functional dimensions: physical functioning, physical role limitations, pain, energy/vitality, emotional role limitations, social functioning, mental health, and general health perceptions. One additional item measures health change over the past year. The scores on each dimension, range from 0 (worst health state) to 100 (best health state). The first four dimensions add up to the Physical Component Summary (PCS) and the latter to the Mental Component Summary (MCS). PCS and MCS reliability were 0.82 and 0.85 , respectively ${ }^{[19]}$.

Data were analysed using Statistical Package for Social Science (SPSS) programme version 19. The analysis of SF36 was done by using a special syntax. Multivariate analysis was preceded once assumptions were fulfilled. Multiple linear regressionswere used to determine the associations between factors and quality of life. The significant value was set at $\mathrm{p} \leq 0.05$. The significant factors in determining the 8 component of quality of life scores was evaluated using independent $t$ test. Ethical approval was obtained from Malaysia National University Ethical Committee and Malaysia National Medical Research Registry.

\section{Results}

\section{a. Socio-demographic characteristics of caregivers and care recipients}

The age ranges of caregivers were 19 to 90 years old with the mean age of55( \pm 15.86$)$. In term of ethnicity, Chinese were the majority $(57.2 \%)$, followed by Malay $(16.6 \%)$, Iban $(13.8 \%)$ and $12.4 \%$ were Bidayuh, Melanau and others. The majority of caregivers were female (73.8\%), married (89.7\%) and $11.3 \%$ remained single. Meanwhile the education level of caregivers were $22.8 \%$ with no formal education, $27.6 \%$ attended primary school, $38.6 \%$ attended secondary school and $11 \%$ had college or university education. About $72.4 \%$ of caregivers were unemployed and $27.6 \%$ of them were employed. Most of the caregivers were non spousal relationship (63.7\%), majority their own children and took care of patient for more than 2 years with the mean of 3 years ( \pm 3.45 ). Daily caregiving duties lasted for more than 8 hours in $80.7 \%$ caregivers and involved 19.3\% caregivers for less than 8 hours duty. Most of caregivers do not share the burden of caregiving. Meanwhile the mean age for care recipients was $74.9( \pm 8.47)$ with range from 60 to 97 years old. The majority of care recipients were female (57.2\%), had no formal education(69\%), majority having type II dementia $(44.2 \%)$ and $30.3 \%$ of them had behavioural problems(see Table 1 ). 


\begin{tabular}{|c|c|c|}
\hline Variables & Caregiver $\mathrm{n}(\%)$ & Care recipient n (\%) \\
\hline \multicolumn{3}{|l|}{ Age (years) } \\
\hline $18-30$ & $5(3.4)$ & \\
\hline $31-40$ & $19(13.1)$ & \\
\hline $41-50$ & $43(29.7)$ & \\
\hline $51-60$ & 30 (20.7) & \\
\hline$>60$ & $48(33.1)$ & \\
\hline $60-70$ & & $48(33.1)$ \\
\hline $71-90$ & & $91(62.8)$ \\
\hline$>90$ & & $6(4.1)$ \\
\hline \multicolumn{3}{|l|}{ Gender } \\
\hline Male & $38(26.2)$ & $62(42.8)$ \\
\hline Female & $107(73.8)$ & $83(57.2)$ \\
\hline \multicolumn{3}{|l|}{ Race } \\
\hline Chinese & $83(57.2)$ & $77(53.1)$ \\
\hline Malay & $24(16.6)$ & $26(17.9)$ \\
\hline Iban & $20(13.8)$ & $19(13.1)$ \\
\hline Bidayuh & $15(10.3)$ & $15(10.3)$ \\
\hline Melanau & $2(1.4)$ & $3(2.1)$ \\
\hline Others & $1(0.7)$ & $5(3.4)$ \\
\hline \multicolumn{3}{|c|}{ Marital status } \\
\hline Married & $130(89.7)$ & $83(55.9)$ \\
\hline Single & $15(10.3)$ & $64(44.1)$ \\
\hline \multicolumn{3}{|l|}{ Education } \\
\hline Informal & $33(22.8)$ & $100(69.0)$ \\
\hline Lower & $96(66.2)$ & $41(28.3)$ \\
\hline Tertiary & $16(11.0)$ & $4(2.8)$ \\
\hline \multicolumn{3}{|c|}{ Employment } \\
\hline Employed & $40(27.6)$ & \\
\hline Unemployed & $105(72.4)$ & \\
\hline \multicolumn{3}{|c|}{ Household income } \\
\hline$<770$ & $42(29.0)$ & \\
\hline$\geq 770$ & $103(71.0)$ & \\
\hline \multicolumn{3}{|l|}{ Relationship } \\
\hline Spouse & $54(37.3)$ & \\
\hline Non spouse & $91(62.7)$ & \\
\hline \multicolumn{3}{|c|}{ Caregiving Characteristics } \\
\hline \multicolumn{3}{|l|}{ Duration } \\
\hline$<2$ years & $69(47.6)$ & \\
\hline$>2$ years & $76(52.4)$ & \\
\hline \multicolumn{3}{|c|}{ Hours of care } \\
\hline$<8$ hours & 23(19.3) & \\
\hline$\geq 8$ hours & $117(80.7)$ & \\
\hline \multicolumn{3}{|c|}{ Share burden } \\
\hline Yes & 19(13.1) & \\
\hline No & $126(86.90$ & \\
\hline \multicolumn{3}{|c|}{ Type of dementia } \\
\hline Mild & & $20(13.8)$ \\
\hline Moderate & & $61(42.1)$ \\
\hline Severe & & $64(44.1)$ \\
\hline \multicolumn{3}{|l|}{ Behaviour } \\
\hline Yes & & $44(30.3)$ \\
\hline No & & 101(69.7) \\
\hline
\end{tabular}

Table 1: Socio-demographic of caregivers and patient $(n=145)$ 
b. Quality of life score SF36

\begin{tabular}{lllll}
\hline Domain & Mean & SD & 95\% CI & p value \\
\hline Role emotion & 78.6 & 39.99 & $(75.05,85.2)$ & $0.000^{* *}$ \\
Role physical & 85.8 & 46.44 & $(56.05,71.3)$ & $0.000^{* *}$ \\
Bodily pain & 66.9 & 23.55 & $(63.04,70.8)$ & $0.000^{* *}$ \\
Vital/Energy & 69.5 & 16.33 & $(66.8,72.1)$ & $0.000^{* *}$ \\
General health & 45.8 & 21.06 & $(42.3,49.3)$ & $0.000^{* *}$ \\
Social function & 68.6 & 27.95 & $(64.03,73.2)$ & $0.000^{* *}$ \\
Physical function & 63.7 & 46.44 & $(82.4,89.1)$ & $0.000^{* *}$ \\
Mental health & 71.9 & 19.33 & $(68.8,75.1)$ & $0.000^{* *}$ \\
\hline Physical Component & 44.7 & 9.46 & $(43.1,46.2)$ & $0.000^{* *}$ \\
Mental Component & 49.1 & 10.98 & $(47.3,50.9)$ & $0.000^{* *}$ \\
\hline
\end{tabular}

**significant level at $p \leq 0.05$

Table 2: Quality of life score among dementia caregivers

\section{c. Multivariate Analysis}

i. $\quad$ Factors associated with mental composite score and physical composite score

Table 3 showed factors associated with mental composite score and physical composite score. The significant factors associated with MCS (mental composite score) was behaviour problem of the care recipients $(\mathrm{p}<0.05)$. Meanwhile significant factors associated with PCS were employment and marital status $(\leq 0.05)$. The other factors were found to be not significant $(\mathrm{p}>0.05)$.

\begin{tabular}{llllll}
\hline Variables & \multicolumn{3}{l}{ MLR } & & \\
\hline & $\begin{array}{l}\text { Regression } \\
\text { Coefficient } \\
(\boldsymbol{B})\end{array}$ & $\boldsymbol{S E}$ & $\boldsymbol{t}$ stat & $\boldsymbol{p}$ value & $\mathbf{9 5 \%} \boldsymbol{C I}$ \\
\hline MCS & & & & \\
Constant & 41.21 & 3.47 & 11.88 & $\mathbf{0 . 0 0 0 * *}$ & $(34.36,48.07)$ \\
Behaviour problem & 5.19 & 1.93 & 2.69 & $\mathbf{0 . 0 3} * *$ & $(2.54,10.30)$ \\
Race (Chinese) & -5.54 & 2.38 & -2.32 & $\mathbf{0 . 0 2 2} * *$ & $(-10.26,-0.81)$ \\
& & & & & \\
\hline PCS & 45.15 & 0.95 & 47.65 & $\mathbf{0 . 0 0 0}$ *** & $(43.90,47.60)$ \\
Constant & -4.13 & 8.54 & -2.50 & $\mathbf{0 . 0 1 3} * *$ & $(-7.77,-0.91)$ \\
Employment status & 4.64 & 2.18 & 2.12 & $\mathbf{0 . 0 3 5 * *}$ & $(0.32,8.95)$ \\
Mild dementia & & & & &
\end{tabular}

**significant level at $\mathbf{p} \leq \mathbf{0 . 0 5}$. Model fit; adjusted $R^{2}=19 \%$, assumption met, no interaction, no multicollinearity.

Table 3: Factors associated with Mental Component Score and Physical Composite Score

\section{d. Description of significant factors effects on 8 components of SF36}

Among the caregivers, there was significant different in the score of component of SF36 due to behavioural problem of the care recipients namely role emotion, energy, mental health and MCS ( $<<0.05)$ (see Table 4). Meanwhile based on employment status, there were significant different in score of role emotion, role physical, general health, social function and PCS $(\mathrm{p} \leq 0.05)$ among the employed and unemployed caregivers (see Table 5). None of the finding showed significant different in the component score among race (Chinese and Non-Chinese) and type of dementia ( $p>0.05)$. 
Quality Of Life Among Caregivers Of Elderly With Dementia And Its Associated Factors

\begin{tabular}{llll}
\hline Domain & Behaviour Mean(SD) & $\begin{array}{l}\text { No behaviour } \\
\text { Mean(SD) }\end{array}$ & p value \\
\hline Role emotion & $65.2(46.0)$ & $84.7(35.6)$ & $\mathbf{0 . 0 0 6 * *}$ \\
Role physical & $52.8(49.5)$ & $68.6(44.4)$ & 0.058 \\
Bodily pain & $62.5(24.7)$ & $68.9(22.9)$ & 0.134 \\
Energy & $63.4(16.9)$ & $72.3(15.4)$ & $\mathbf{0 . 0 0 2 * *}$ \\
General health & $42.4(22.8)$ & $47.3(20.2)$ & 0.190 \\
Social function & $63.0(27.9)$ & $71.1(27.7)$ & 0.108 \\
Physical function & $83.9(20.9)$ & $86.6(20.5)$ & 0.461 \\
Mental health & $65.8(22.5)$ & $74.7(17.1)$ & $\mathbf{0 . 0 0 9 * *}$ \\
PCS & $43.6(9.7)$ & $45.1(9.4)$ & 0.385 \\
MCS & $45.1(12.5)$ & $50.9(9.8)$ & $\mathbf{0 . 0 0 3 * *}$ \\
\hline
\end{tabular}

**significant level at $p \leq 0.05$

Table 4: SF-36 Scores Based on Patient's Behaviour

\begin{tabular}{llll}
\hline Domain & Employed Mean(SD) & $\begin{array}{l}\text { Non-employed } \\
\text { Mean(SD) }\end{array}$ & p value \\
\hline Role emotion & $66.7(45.9)$ & $83.2(36.7)$ & $\mathbf{0 . 0 2 6}^{* *}$ \\
Role physical & $48.8(49.7)$ & $69.4(44.1)$ & $\mathbf{0 . 0 1 6}^{* *}$ \\
Bodily pain & $61.6(28.3)$ & $68.9(21.3)$ & 0.091 \\
Energy & $67.3(19.5)$ & $70.4(14.9)$ & 0.304 \\
General health & $39.1(23.4)$ & $48.4(19.6)$ & $\mathbf{0 . 0 1 8}^{* *}$ \\
Social function & $56.3(30.1)$ & $73.3(25.7)$ & $\mathbf{0 . 0 0 1}^{* *}$ \\
Physical function & $81.9(26.1)$ & $87.2(18.0)$ & 0.163 \\
Mental health & $70.3(19.1)$ & $72.6(19.5)$ & 0.529 \\
PCS & $41.7(12.21)$ & $45.8(7.98)$ & $\mathbf{0 . 0 2 2}^{* *}$ \\
MCS & $46.5(12.26)$ & $50.0(10.3)$ & 0.084 \\
\hline
\end{tabular}

**significant level at $p \leq 0.05$

Table 5: SF-36 Scores Based on Employment Status

\section{Discussion}

The objectives of the study were to identify the factors associated with quality of life of dementia caregivers. Generally this group of caregivers experienced physical and mental health problems as reflected by lower mean score of PCS and MCS. The mean score of each component was found to be slightly higher compare to stroke patients ${ }^{[20]}$ and was slightly lower compare to general population in Malaysia ${ }^{[21]}$. However, the PCS and MCS mean scores were found to be similar with stroke population ${ }^{[20]}$. Meanwhile two studies found that informal dementia caregivers experience higher ratesof mental health and physical health problems when compared to their agecounterparts who are not caregivers ${ }^{[22,23]}$. In comparison of MCS and PCS, they were facing more problem in mental health as found by significant association between MCS and many factors $(\mathrm{p} \leq 0.05)$.

In the multiple linear regression analysis showed that the behaviour and Chinese racewas significantly associated with MCS $(p \leq 0.05)$. Previous study had found that the care recipients behaviour were most significant predictors in causing the burden ${ }^{[24]}$ thus, this would affect their quality of life. This was related Behavioural Psychological Symptoms of Dementia (BPSD) which commonly occurs in Alzheimer's dementia ${ }^{[25]}$, they will have neuropsychiatric symptoms such as disturbed behaviour, agitation, wandering which really irritating and annoying to the caregivers and family resulting in depression ${ }^{[3]}$. In a study by Adam et al. ${ }^{[26]}$ described models of the dementia caregiving stress process specifythat the impairments and behavioural problems of the person withAlzheimer's disease or related disorder (ADRD) and primarysubjective stressors, such as burden, along with secondary stressorsand appraisals, lead to negative outcomes such as depression. A study on abuse byfamily caregivers found that depression in the caregiver was among the riskfactors for lowerquality care provided ${ }^{[25]}$. None of the previous study support the finding of Chinese race had significant lower score of MCS. Chinese was known to practise filial piety norms; however this factor was not a protective against poor quality of life. There were many other factors could contribute such as family support, coping strategies and so on. 
Meanwhile, the factors associated with PCS were mild dementia and employment status. The caregivers taking care of mild dementia patients had higher score of quality of life compare to other types. This was related to the dementia severity which affects their quality of life indirectly. It was found in previous study that double burden due to employment and caregiving did affect caregivers' quality of life ${ }^{[28]}$. So as the marital status, burden of taking care of family, doing house chores and at the same time provide caregiving can lead to physical exhaustion.In addition to providing informal care for older individuals with dementia, manycaregivers remain in the work force. The amount of time required to care for an olderindividual with dementia can create a strain on the working caregiver ${ }^{[28]}$. In a study among working informal caregivers of older veterans with progressive dementia, caregiverdepression was positively associated with both the probability of missing any time atwork due to caregiving responsibilities and the number of hours missed due to caregivingresponsibilities [29].

In term of each domain of SF36,the caregivers caring for the care recipients with the behaviour problem had significantly lower score in the components of emotion, energy, mental health and MCS. Beach et al. ${ }^{[27]}$ found that the behavioural symptoms of care recipients do affect the psychological wellbeing of the caregivers. These were correlated with annoying behaviour from care recipient that cause them to be emotionally unstable, loss of energy, depressed or anxious. In the group of employed caregivers, the caregivers had significant lower score in term of role emotion, role physical, general health perception and social function.

\section{Conclusion}

These were the first study that determine quality of life and associated factors in dementia caregivers in local setting. The factors associated with lower MCS among this group werepatients'behavioural symptoms and being a Chinese. Meanwhile factors affecting PCS were employment status and type of dementia. The most affected domain in quality of life due to patient behaviour was role emotion, energy and physical function. Meanwhile for employed caregivers the most affected domain was role of emotion, role physical, general health and social function. Limitation of this study was related to sampling method as the sampling was purposive, due to limited numbers of dementia patients. Even though this result could not be generalized, it was able to represent the similar population. Study design like a cohort study would be better off in comparison to cross sectional study to identify the causal effect of factors affecting quality of life. These probably can be done in the near future to evaluate the impact of factors on quality of life of dementia in our local setting. In conclusion, these group of caregivers experiencing significant lower physical and mental health score of quality of life. Further intervention such as local community support should be created in order to help these caregivers.

\section{Acknowledgement}

Authors would like to thanks all the hospital staff who gave their help during data collection.

\section{References}

[1] FS.Ong, DR.PhillipsandTA.Hamid.Ageing in Malaysia: Progress and prospect.Routledge, 2009,138-160.

[2] RJV.Montgomery and KD.Koloski. Family Caregiving: Change, Continuity and Diversity. In P. Lawton and R. Rubenstein (Eds.), Alzheimer's Disease and Related Dementias: Strategies in Care and Research. New York: Springer, 2000.

[3] S.Mohamed, R.Rosenbeck, CG.Lyketsos and LS.Schneider.Caregiver Burden in Alzheimer Disease: Cross-Sectional and Longitudinal Patient. The American Journal of Geriatric Psychiatry, 18(10), 2010, 917-928.

[4] SR.Riedijk, ME.De Vugt,HJ.Duivenvoorden, MF.Niermeijer, JC.VanSwieten, FRJ Verhey and ATibben. Caregiver Burden, Health-Related Quality of Life and Coping in Dementia Caregivers:A Comparison of Frontotemporal Dementia and Alzheimer's Disease. Dementia Geriatric Cognitive Disorder, 22, 2006, 405-412.

[5] JC.Arango-Lasprilla, T.Lehan, A. Drew, A. Moreno, X.Deng and M. Lemos. Health-Related Quality of Life in Caregivers of Individuals With Dementia From Colombia. American Journal of Alzheimer's Disease \& Other Dementia, 25(7), 2010, 556-561.

[6] RD. Pattanayak, R. Jena, D.Vibha, SK. Khandelwal and M.Tripathi. Coping and its relationship to quality of life in dementia caregivers.Dementia, O(0), 2011,1-10.

[7] SL. Hughes, A.Giobbie-Hurder, FM. Weaver, JD.Kubal and W. Henderson. Relationship Between Caregiver Burden and HealthRelated Quality of Life. The Gerontologist, 39(5), 1999, 534-545.

[8] AM. Hubley, D. Hemingway and AC. Michalos.A Comparison of Older Informal Caregivers and Non-Caregivers Living in NonMetropolitan Area.Social Indicators Research, 61, 2003, 241-258.

[9] Alzheimer's Disease International. 2010. Dementia in Asia Pacific: The Epidemic is here. http://www.alz.co.uk/research/asiapacificreport.html.[2 Dec 2011].

[10] C. Lai and J.Chung. Caregivers' informational needs on dementia and dementia care. Asian Journal of Gerontology Geriatric, 2(2), 2007, 78-87.

[11] KS. Shaji, RK. George, MJ. Prince and KS. Jacob. Behavioral symptoms and caregiver burden in dementia. Indian $J$ Psychiatry,5(1), 2009, 45-49.

[12] R. Schulzand SR. Beach. Caregiving as a risk factor for mortality: The caregiver health effects study. JAMA, 282, 1999, $2215-2222$.

[13] R. Schulz and LM.Martire. Family caregiving of persons with dementia: Prevalence, health effects, and support strategies. American Journal of Geriatric Psychiatry, 12 (3), 2004, 240-249.

[14] R. Schulz and PR. Sherwood.Physical and Mental Health Effects of Family Caregiving.Am J Nurs,108(9 Suppl), $2008,23-27$.

[15] MJL. Graff, M. Vernooij-Dassen, M.Thijssen, J. Dekker, H. Willibrordand MG. OldeRikkert. Effects of Community Occupational Therapy on Quality of Life, Mood, and Health Status in Dementia Patients and Their Caregivers: A Randomized Controlled Trial. Journal of Gerontology, 62(9), 2007, 1002-1009. 
[16] J. Zainuddin, JT. ArokiasamyandPJH.Poi. Caregiving Burden is Associated with Short rather than Long Duration of Care for Older Persons.Asia Pac J Public Health, 15, 2003, 88-95.

[17] B. Schoenmakers, F. Buntinx and J. Delepeleire.Factors determining the impact of care-giving on caregivers of elderly patientswithdementia.A systematic literature review.Elsevier, 66, 2010, 191-200.

[18] J.E. Ware, M. KosinskiandS.D. Keller. SF36: Physical and Mental Summary Scales: A User's Manual. Boston: The Health Institute, New England Medical Center, 1994.

[19] S. Sararaks, AB. Azman, LL. Low, B. Rugayah, AM. Aziah, LN. Hooi, M. Abdul Razak, MR. Norhaya, KB. Lim, AA. Azian and S. Geeta. Validity and reliability of the SF-36: the Malaysian context. Med J Malaysia.June, 60(2), 2005, 163-79.

[20] AB Azman, S Sararaks, B Rugayah, LL. Low, AA.Azian, S.Geeta\&CT.Tiew. Quality of life of the Malaysian generalpopulation: results from a postal surveyusing the SF-36. Med J Malaysia, 58(5), 2005, 694-711.

[21] M. Pinquart and S. Sorensen. Differences between caregivers and noncaregiversin psychological health and physical health: A meta-analysis. Psychologyand Aging, 18, 2003, 250-267.

[22] R. Schulz and LM.Martire. 2004. Family caregiving of persons with dementia:Prevalence, health effectsand support strategies. The American Journal of GeriatricPsychiatry, 12(3), 240-249.

[23] AV. Kaufmann, JI.Kosberg, JD. Leeper and M. Tang. Social Support, Caregiver Burden, and Life Satisfaction in a Sample of Rural African American and White Caregivers of Older Persons With Dementia. Journal of Gerontological Social Work, 53, 2010, 251269

[24] S. Mohamed, CG. Lyketsos and LS.Scheneider. Caregiver Burden in Alzheimer's Disease: Cross Sectional and Longitudinal Patient Correlates. The American Journal of Geriatric Psychiatry, 18(10), 2010, 917-928.

[25] L. Hinton, M. Haan, S. Geller and D. Mungas. Neuropsychiatric Symptoms in Latino Elders With Dementia or Cognitive Impairment Without Dementia and Factors That Modify Their Association With Caregiver Depression. The Gerontologist, Vol. 43(5), 2002, 669-677.

[26] KB. Adams,MJ. McClendon and KA. Smyth. Personal losses and relationship quality in dementia caregiving.Dementia,7, 2008, 301-321.

[27] SR. Beach, R. Schulz, R. Williamson, LS. Miller, MF. Weiner and CE.Lance.Risk factors for potentially harmful informal caregiver behavior.Journal ofthe American Geriatric Society, 53, 2005, 255-261.

[28] C. Farran, D.Loukissa, S.Perraud and O.Paun.Alzheimer's disease caregiving information and skills. Part II: Family caregiver issues and concerns. Research in Nursing \& Health, 27(1), 2004, 40-51.

[29] MR. Wilson, CH.VanHoutven, SC.Stearns and EC.Clipp. Depression and Missed Work among Informal Caregivers of Older Individuals with Dementia.Journal of Family Economic Issue, 28, 2007, 684-698. 